\title{
Recommendations for Clinical Decision-making in Children with Type 1 Diabetes and Celiac Disease: Type 1 Diabetes and Celiac Disease Joint Working Group Report
}

\author{
(D) Şükrü Hatun1, (D) Buket Dalgıç², (D) Damla Gökşen³, (D) Sema Aydoğdu4, (D) Şenay Savaş Erdeve5, (D) Zarife Kuloğu6, (D) Yaşar Doğan7, \\ (1) Zehra Aycan8, (D) Gül Yeşiltepe Mutlu1, (1) Nuray Uslu Kızılkan9, (D) Alev Keser10, (D) Ömer Faruk Beşer11, (D) Mehmet Nuri Özbek12, \\ (D) Aysun Bideci13, (D) Deniz Ertem ${ }^{14}$, (D) Olcay Evliyaoğlu15, (D) Beyza Eliuz Tipici16, (D) Tuğba Gökçe ${ }^{1}$, (D) Serra Muradoğlu1, \\ (D) Orhun Çı̆̆ Taşkın17, (D) Tuğba Koca18, (D) Filiz Tütüncüler ${ }^{19}$, (D) Firdevs Baş20, (D) Feyza Darendeliler20, (D) Mukadder Ayşe Selimoğlu21 \\ ${ }^{1}$ Koç University Faculty of Medicine, Department of Pediatric Endocrinology and Diabetes, Istanbul, Turkey \\ 2Gazi University Faculty of Medicine, Department of Pediatrics, Division of Pediatric Gastroenterology, Ankara, Turkey \\ ${ }^{3}$ Ege University Faculty of Medicine, Department of Pediatric Endocrinology, Izmir, Turkey \\ ${ }^{4}$ Ege University Faculty of Medicine, Department of Pediatric Gastroenterology, Izmir, Turkey \\ 5 University of Health Sciences Turkey, Ankara Dr. Sami Ulus Obstetrics and Gynecology and Pediatrics Training and Research Hospital, Clinic of \\ Pediatric Endocrinology, Ankara, Turkey \\ ${ }^{6}$ Ankara University Faculty of Medicine, Department of Pediatrics, Division of Pediatric Gastroenterology, Ankara, Turkey \\ 7 Firat University Faculty of Medicine, Department of Pediatric Gastroenterology, Elazı̆g, Turkey \\ ${ }^{8}$ Ankara University Faculty of Medicine, Department of Pediatric Endocrinology, Ankara, Turkey \\ ${ }_{9}$ Koç University Hospital, Department of Pediatric Gastroenterology, Istanbul, Turkey \\ ${ }^{10}$ Ankara University Faculty of Health Sciences, Department of Nutrition and Dietetics, Ankara, Turkey \\ 11 istanbul University-Cerrahpaşa, Cerrahpaşa Faculty of Medicine, Department of Pediatric Gastroenterology, Hepatology, and Nutrition, \\ istanbul, Turkey \\ 12 University of Health Sciences Turkey, Gazi Yaşargil Training and Research Hospital, Clinic of Pediatric Endocrinology, Diyarbakır, Turkey \\ ${ }^{13}$ Gazi University Faculty of Medicine, Department of Pediatric Endocrinology and Diabetes, Ankara, Turkey \\ 14Marmara University Faculty of Medicine, Department of Pediatric Gastroenterology, Hepatology and Nutrition, Istanbul, Turkey \\ 15 istanbul University-Cerrahpaşa, Cerrahpaşa Faculty of Medicine, Department of Pediatrics, Division of Pediatric Endocrinology, istanbul, Turkey \\ 16istanbul University, istanbul Faculty of Medicine, Department of Nutrition and Dietetics, Istanbul, Turkey \\ 17 Koç University Faculty of Medicine, Department of Pathology, Istanbul, Turkey \\ 18 Süleyman Demirel University Faculty of Medicine, Department of Pediatric Gastroenterology, Hepatology and Nutrition, Isparta, Turkey \\ ${ }^{19}$ Trakya University Faculty of Medicine, Department of Pediatrics, Division of Pediatric Endocrinology, Edirne, Turkey \\ 20istanbul University, Istanbul Faculty of Medicine, Department of Pediatric Endocrinology, Istanbul, Turkey \\ ${ }^{21}$ Memorial Ataşehir/Bahçelievler Hospitals, Clinic of Pediatric Gastroenterology, Hepatology and Nutrition, İstanbul, Turkey
}

\begin{abstract}
It is well-known that in children with type 1 diabetes (T1D), the frequency of Celiac disease (CD) is increased due to mechanisms which are not fully elucidated but include autoimmune injury as well as shared genetic predisposition. Although histopathologic examination is the gold standard for diagnosis, avoiding unnecessary endoscopy is crucial. Therefore, for both clinicians and patients' families, the diagnosis of $\mathrm{CD}$ remains challenging. In light of this, a joint working group, the Type 1 Diabetes and Celiac Disease Joint Working Group, was convened, with the aim of reporting institutional data and reviewing current international guidelines, in order to provide a framework for clinicians. Several controversial issues were discussed: For CD screening in children with T1D, regardless of age, it is recommended to measure tissue transglutaminase-immunoglobulin A (tTG-IgA) and/or endomysial-IgA antibody due to their high sensitivity and specificity. However, the decision-making process based on tTG-IgA titer in children with T1D is still debated, since tTGIgA titers may fluctuate in children with T1D. Moreover, seronegativity may occur spontaneously. The authors' own data showed that
\end{abstract}

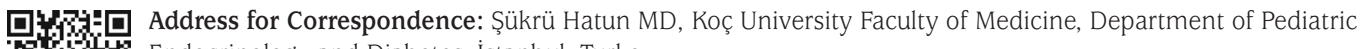
Endocrinology and Diabetes, İstanbul, Turkey Phone: + 905323468006 E-mail: sukruhatun@gmail.com ORCID: orcid.org/0000-0003-1633-9570

${ }^{\circ}$ Copyright 2022 by Turkish Pediatric Endocrinology and Diabetes Society

The Journal of Clinical Research in Pediatric Endocrinology published by Galenos Publishing House.
}

Conflict of interest: None declared Received: 18.05 .2021 Accepted: 10.08 .2021 
most of the cases who have biopsy-proven CD had tTG-IgA levels 7-10 times above the upper limit. The decision for endoscopy based solely on tTG-IgA levels should be avoided, except in cases where tTG-IgA levels are seven times and above the upper limit. A closer collaboration should be built between divisions of pediatric endocrinology and gastroenterology in terms of screening, diagnosis and follow-up of children with T1D and suspicious CD.

Keywords: Children, type 1 diabetes, Celiac disease, anti-tissue transglutaminase-IgA

\section{Introduction}

Among children with type 1 diabetes (T1D), the prevalence of Celiac disease (CD) is higher than in the general population (1.6-16.4\% vs $0.7 \%$ ) since they are susceptible to autoimmune damage to several organ systems (1). Therefore, the screening of children with T1D for CD is critical, and the current screening protocol includes the measurement of tissue transglutaminase-IgA (tTG-IgA) levels regardless of symptom status, followed by endoscopic biopsy in those with positive tTG-IgA titers $(2,3)$. The treatment then involves the institution of a gluten-free diet. Overall, the timing of tTG-IgA measurements has an important role in the decision-making process and the management of the patients.

From the perspective of pediatric endocrinologists, pediatric gastroenterologists and families, avoiding clinically unjustified endoscopies is just as critical as the timely diagnosis of $\mathrm{CD}$. Furthermore, variations exist in the indications for endoscopy and treatment among different countries and centers (4).

This report is intended to convey the most up-to-date information regarding the current diagnostic algorithms, the role of a gluten-free diet, the epidemiologic data in Turkey, recent developments in the literature, and recommendations of international societies in relation to $\mathrm{CD}$ in children with T1D. This report was prepared by professionals assigned by the administrative boards of "Pediatric Endocrinology and Diabetes Association" and "Turkish Society of Pediatric Gastroenterology, Hepatology and Nutrition" and was based on data from several centers and discussions that took place at three different meetings.

The goal of this report was to further detail the current recommendations by international societies and to provide a basic framework to be used by practicing physicians.

\section{Main Questions That were Discussed in the Joint Meetings}

- What is the prevalence of $\mathrm{CD}$ in children with T1D in Turkey? What are the main issues regarding the screening and diagnosis?

- In general, how long after the diagnosis of T1D would tTGIgA antibody levels be reliable?
- What is the rate of transient tTG-IgA positivity and how does this affect diagnosis?

- Would making the decision to perform endoscopy according to tTG-IgA titers measured just after a diagnosis of T1D in children with no symptoms and family history of $\mathrm{CD}$ lead to unnecessary invasive procedures?

- Does tTG-IgA positivity and incidence of CD in children with T1D vary depending on age and time after the initial diagnosis T1 D? Is autoimmune thyroiditis an additional risk factor?

- Would it be beneficial to conduct multidisciplinary meetings for clinical decision-making in caring for children with T1D and a diagnosis of/suspicion of CD? Alternatively, should this process be under the responsibility of pediatric gastroenterologists alone?

- From the perspective of pathologists, what are the basic issues encountered in the diagnosis of $\mathrm{CD}$ ?

- Why has gluten-free diet become so popular among the public? What do the scientific data suggest?

- What are the issues associated with gluten consumption apart from in the context of $\mathrm{CD}$ ?

- What do the families experience in terms of the possibility of having a diagnosis of $\mathrm{CD}$, the diagnostic process and the period after the diagnosis? What are their concerns? Does a gluten-free diet have any role in preventing T1D?

- In children who are already diagnosed with T1D, would a gluten-free diet reduce the risk of acquiring CD? Would this diet have any impact on the autoimmune destruction of beta-cells?

- How should we follow children with high tTG-IgA titers but normal endoscopic findings? Should a gluten-free diet be recommended?

- How should the dietary management of a child with T1D and $\mathrm{CD}$ be?

\section{Results and Suggestions}

\section{The Relationship Between Diabetes and Celiac Disease}

1. The prevalence of positive $\mathrm{CD}$ autoimmunity and overt CD was $14.3 \%$ [95\% confidence interval (CI): 11 17] and 
$8.5 \%$ (95\% CI: 5-10), 15- and 8-times higher than the general pediatric population, respectively (5). According to international studies, the prevalence of biopsy-proven $\mathrm{CD}$ ranges between 1.6-16.4\% among people with T1D $(6,7,8,9,10)$.

2. In a recently published study including 52751 children with T1D from the US, Germany, Austria, England and Australia the prevalence of CD was found to be $3.5 \%$ (4). In general, the risk of receiving a diagnosis of biopsy-proven $\mathrm{CD}$ is higher before the age of 5 years and within the first five years after the diagnosis of T1D. Concomitant autoimmune thyroid disease further increases this risk (3).

3. $\mathrm{CD}$ is asymptomatic in $85 \%$ of children with T1D who have biopsy-proven diagnosis. As a result, it is necessary to screen for $C D$ in this population.

4. According to studies from Turkey, the prevalence of biopsy-proven CD in children with T1D is 3.5-12.2\% $(11,12)$.

5. During the meetings for the preparation of this report, data gathered by the following institutions were presented to seek answers to the previously posed questions: Koç University, Gazi University, Ege University, Ankara University, Dr. Sami Ulus Children's Hospital, Cerrahpaşa Medical Faculty and Elazığ Firat University:

- In the last five years, 1061 children with T1D were followedup at Koç University. A total of 401 whose CD screening was conducted in Koç University Hospital were evaluated. tTGIgA positivity was detected in $61 \%$ of CD cases in the first year, $37 \%$ between the first and fifth years, and in $2 \%$ after the fifth year of T1D diagnosis. The prevalence of biopsyproven $\mathrm{CD}$ was $3.7 \%$ in this cohort.

- In the last 10 years, 559 children were diagnosed with T1D at Gazi University. The prevalence of biopsy-proven CD was $3.4 \%$ in this cohort. Of these patients, $82.4 \%$ were asymptomatic. CD diagnosis was made within the first two years of T1D diagnosis in $50 \%$, and $94 \%$ were diagnosed within the first 5 years.

- Data from Ege University encompassed 1300 children with T1D and the prevalence of biopsy-proven CD was $1.9 \%$ in this cohort. $72 \%$ of the cohort was asymptomatic and $59 \%$ were diagnosed within two years following the diagnosis of T1D.

- Data from Ankara University included 158 children with T1D and the prevalence of biopsy-proven CD was $4.4 \%$. $85 \%$ of the cases received a diagnosis within the first 5 years following the diagnosis of T1D.

- Data from Dr. Sami Ulus Children's Hospital included a nine-year period, during which 550 children were diagnosed with T1D. In this cohort, $5.2 \%$ had biopsy-proven CD. In the first year, $72.4 \%$ of the children with $\mathrm{CD}$ were diagnosed with CD.

- Data from Cerrahpaşa Medical Faculty included 100 children, among whom $4 \%$ were diagnosed with CD based on histopathology.

- Data from Firat University included a 14-year period, during which 453 children were diagnosed with T1D. Among these, the prevalence of biopsy-proven CD was $5.5 \%$. $76 \%$ of the patients were asymptomatic and $64 \%$ were diagnosed within the first year following the diagnosis of T1D.

6. In the follow-up of children with $\mathrm{T} 1 \mathrm{D}$, the current recommendations for the timing of Celiac serology screening include within first two years and five years after diagnosis of $\mathrm{T} 1 \mathrm{D}$ or every year, but the recommendations regarding the frequency of screening after five years following T1D diagnosis are less clear. While the risk of developing CD decreases significantly after this 5-year mark, the possibility of CD should still be kept in mind. In addition to the above recommendations, screening should be conducted in case of any of the below:

- Symptom and laboratory findings suggestive of CD,

- First degree relative with a diagnosis of CD,

- Unexplained frequent hypoglycemia.

\section{Screening Tests and Their Interpretation}

1. After checking that the child is consuming normal quantities of gluten, in children with normal serum IgA values for age, tTG-IgA measurements should be used as an initial test regardless of age (2). If serum IgA levels are found to be low for age or $<0.2 \mathrm{~g} / \mathrm{L}$ in children older than three years old, IgG based tests (deaminated gliadin peptide, EMA or tTG) should be use. tTG-IgA titers are reported as international unit (IU) or relative unit (RU). The upper limits for IU and RU are 20 and 1, respectively. Threshold tTGIgA levels that justify performing endoscopy are generally reported as multiples of the upper limit (e.g. 3-fold, 10fold). In addition, recommendations outlined by the specific testing kits should be considered. On the other hand, EMAIgA testing should be conducted with techniques involving immunofluorescence.

2. International studies have reported that tTG-IgA levels show a fluctuating trend in $10.7-41 \%$ of the patients and resolve in 30-40\%, despite continued gluten intake $(5,13,14,15)$. Data from Gazi University indicate that $12.7 \%$ had a fluctuating course; in this group tTG-IgA levels 
were $<3 x$ upper limit of normal (ULN) and the rate of spontaneous resolution of antibodies was $97 \%$. Diyarbakır Gazi Yaşargil Hospital and Koç University Hospital have reported spontaneous antibody resolution rates of $23.3 \%$ and $22 \%$ within five years, respectively (15).

3. In recent years, there has been an increasing debate regarding the threshold tTG-IgA level for offering endoscopy. Data presented by Gazi University have been assessed, and the best cut-off was judged to be $\geq 7$-times the ULN in terms of sensitivity, specificity, negative predictive value and positive predictive value. Data from centers that submitted their data to this committee were also congruent in that the majority of the patients with biopsy-proven CD had tTG-IgA levels $7-10 \mathrm{x}$ the ULN.

4. We therefore recommend that tTG-IgA levels should not be the sole criterion for performing endoscopy, except when tTG-IgA levels $\geq 7 \times$ ULN, there is a family history of CD or the patient has symptoms suggestive of $\mathrm{CD}$. Physicians should keep in mind that during the early stages of T1D, there can be a transient "antibody storm" against not only the pancreatic beta-cells but also other tissues, which may eventually resolve. In children with antibody levels within 3-7 times the ULN and without any of the exceptions highlighted above, antibody test can be repeated at 3-6 months prior to seeking endoscopic evaluation.

5. Despite the increasing data on transient and fluctuating antibody positivity, the European Society of Pediatric Gastroenterology Hepatology and Nutrition (ESPGHAN) and the International Society of Pediatric and Adolescent Diabetes (ISPAD) currently do not detail any recommendations on this issue in their respective guidelines. Therefore, we believe that it would be clinically beneficial if these societies prepared a joint consensus guideline for the diagnosis and management of $\mathrm{CD}$ in children with T1D.

\section{Decision to Perform Endoscopy and Clinical Management}

In the light of the data presented at the meetings and available in the literature, and after taking into consideration the current consensus opinions, the following recommendations regarding the indications for endoscopy and clinical management are set forth below:

1. With the exception of frequent attacks of hypoglycemia and symptoms suggestive of $\mathrm{CD}$, invasive procedures, such as endoscopy, should be planned for the most appropriate date given that the diagnosis of $\mathrm{CD}$ is not considered urgent, and families require time to get accustomed to the diagnosis of T1D.
2. There is no single standard test for measuring antibody levels. Hence, endoscopy should not be undertaken based on tTG-IgA levels measured at another center. Instead a repeat measurement should be conducted prior to deciding on the need for endoscopy.

3. Apart from the cases with tTG-IgA levels $\geq 7 x$ the ULN, tTGIgA levels measured at the time of diagnosis of T1D should not be used to guide the decision to perform endoscopy.

4. Prior to measuring tTG-IgA levels, it should be confirmed that patients have been consuming gluten for at least two weeks.

5. If the tTG-IgA levels are $\leq 3 x$ the ULN there is no indication to perform endoscopy in patients without a family history of $\mathrm{CD}$ or symptoms suggestive of $\mathrm{CD}$. Such patients can be followed up by the pediatric endocrinology department through serial antibody testing.

6. All patients with a tTG-IgA level $>3 x$ the ULN should be referred to the pediatric gastroenterology department as soon as possible.

7. For patients with tTG-IgA levels $\geq 10 x$ the ULN and a second antibody test reveals EMA positivity, the family should be informed that a diagnosis of $\mathrm{CD}$ can be made without further endoscopic evaluation. However, making a definitive diagnosis through endoscopic biopsy may improve compliance to dietary management, especially in the setting of our country.

8. Patients with fluctuating antibody titers and antibody levels $<3 x$ the ULN can be followed up without endoscopy.

9. In patients with tTG-IgA levels between 3-7x the ULN, further diagnostic steps may include EMA-IgA testing followed by endoscopy if EMA positive or immediate endoscopy depending on the center's preference.

10. There is seldom need to perform testing for HLA DQ2 and HLA DQ8 subgroups for the diagnosis of CD. This testing can be useful in ruling out $\mathrm{CD}$ in challenging cases with equivocal biopsy findings.

11. All children with biopsy-proven $C D$ should be managed with a gluten-free diet regardless of the presence of symptoms.

The algorithm prepared through these analyses and committee recommendations are presented in the Figure 1.

\section{Pathology}

1. All patients scheduled for endoscopic evaluation should be on a gluten-containing diet prior to the endoscopy. The relevant clinical data of the patient, including medical 
history, endoscopic findings, laboratory findings, serology, medications, and diet, must be available to the pathologist $(16,17)$.

2. In terms of location and the number of biopsy sites and samples, international guidelines should be followed. As per current recommendations of the American College of Gastroenterology and the American Gastroenterological Association, at least two samples from the duodenal bulb and four samples from the distal duodenum should be obtained (18).
3. To avoid processing artifacts that can interfere with the histopathological interpretation, endoscopy units and the pathology laboratory should be arranged as required. Biopsies should be reported according to the most recent MarshOberhuber classification. Apart from patients with Marsh 0 grading all patients should be followed by both the pediatric endocrinology and gastroenterology departments $(16,19)$.

4. The diagnosis of $\mathrm{CD}$ may require a consensus of pathological, clinical and laboratory findings. Findings of the histopathologic examination should be clinically correlated.
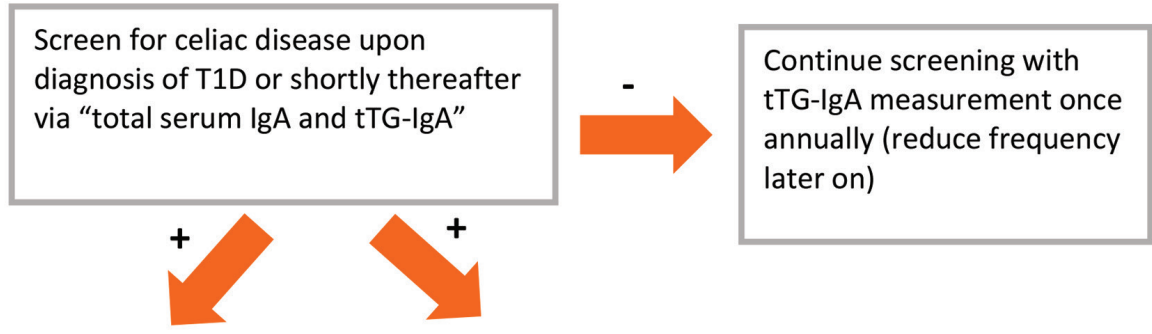

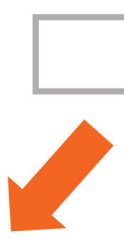

Perform intestinal biopsy if tTG-IgA > 7x ULN
No symptoms

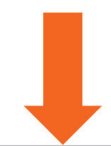

Request pediatric gastroenterology consultation if tTG-IgA is 3-7x ULN

\section{Follow-up with tTG-IgA every 6-12 mo if levels are $<3 x$ (may reduce frequency if no increase) May be followed by} pediatric endocrinology
Symptoms consistent with celiac disease OR unexplained frequent hypoglycemia OR autoimmune thyroid disorder OR family history of celiac disease

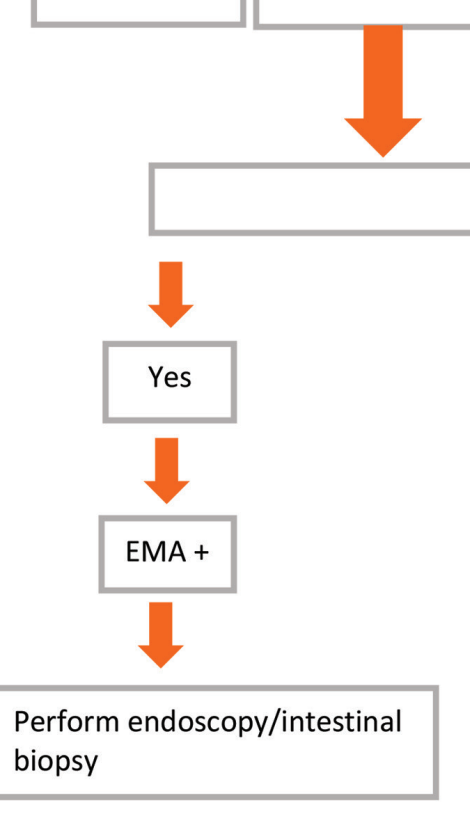

Is it possible to test for EMA

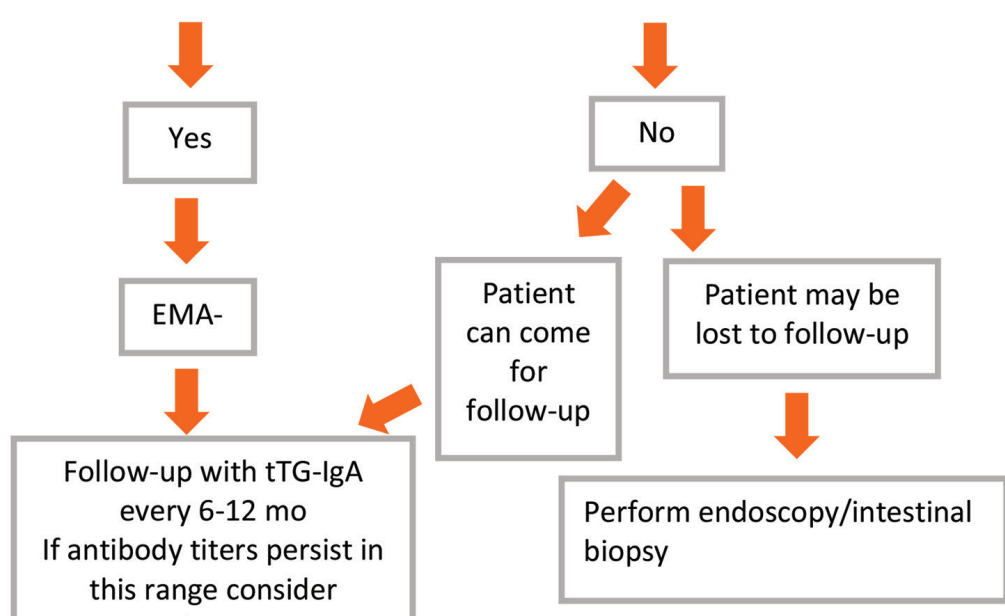

Figure 1. An algorithm for the screening and diagnosis of Celiac disease in children with type 1 diabetes 


\section{Dietary Recommendations}

1. Patients with a diagnosis of CD must follow a strict lifelong gluten-free diet (20). Hence, when CD accompanies T1D, patients need closer follow-up along with more intensive counseling and dietary management (21).

2. A gluten-free diet involves the complete removal of wheat, barley, rye, and their hybrids/products from the diet (Table 1) (21). Nevertheless, conserved foods, premade salad/pasta sauces, some ice creams, charcuterie products such as sausage and pepperoni, premade jams, sugar cubes, premade meat-chicken broth, fruit jelly, malt drinks and beverage powder may include gluten. Other less conspicuous sources of gluten include toothpaste, mouthwash, the glue on stamps and envelopes (21).

3. Patients with CD must inspect whether any orally administered medication, supplement or vitamin includes gluten. Wheat flour and wheat starch are among the products used in drug manufacture. In general, if a medical product does not include wheat flour or wheat starch it is considered to be free of gluten. The amount of gluten contained in a drug is directly related to the amount of wheat flour used in its production. Therefore, if a drug description does not include information about gluten content but mentions wheat flour, that drug should be avoided by patients with CD. Medications may also include other compounds obtained through the processing of wheat flour and starch. Generally, the amount of gluten in a single unit dose of these medications are lower than the gluten amount found in foods labeled as "gluten-free". Oral intake of such medications does not interfere with a gluten-free $\operatorname{diet}(22)$.
4. Some topical products that are applied to the lips and/or the skin may contain wheat germ oil. The gluten content in highly refined wheat germ oil is infinitesimal and its topical application does not interfere with a gluten-free diet (22).

5. Foods with a label that reads "Does not contain gluten" or "Gluten-free" should contain $\leq 20$ ppm of gluten, which can be safely consumed (2).

6. When preparing foods at home, communal use of kitchen equipment without adequate cleaning, especially of the oven and bread maker can lead to contamination with gluten. To prevent contamination, ovens and bread makers should be appropriately cleaned after each use to remove any gluten. Kitchen equipment, such as toasters, that cannot be washed should only be used by the patient. In addition, the use of cooking bags in the oven may reduce the risk of contamination. All gluten-free food products that belong to the patient with CD must be labeled and stored separately in their own drawer/cupboard, on higher racks than the products containing gluten $(21,23)$.

7. It is safer to use stainless steel pots and pans or glass containers when cooking meals for patients with CD. Equipment such as pots, pans and serving spoons should not be made of materials that may have pores (e.g., wood). Prior to use, all equipment should be thoroughly cleaned and separately provided for the patient (24).

8. Children and adolescents with T1D and CD can consume rice, potato, corn (maize), teff, amaranth, buckwheat, quinoa, and sorghum as a source of carbohydrate, since these do not contain gluten (25).

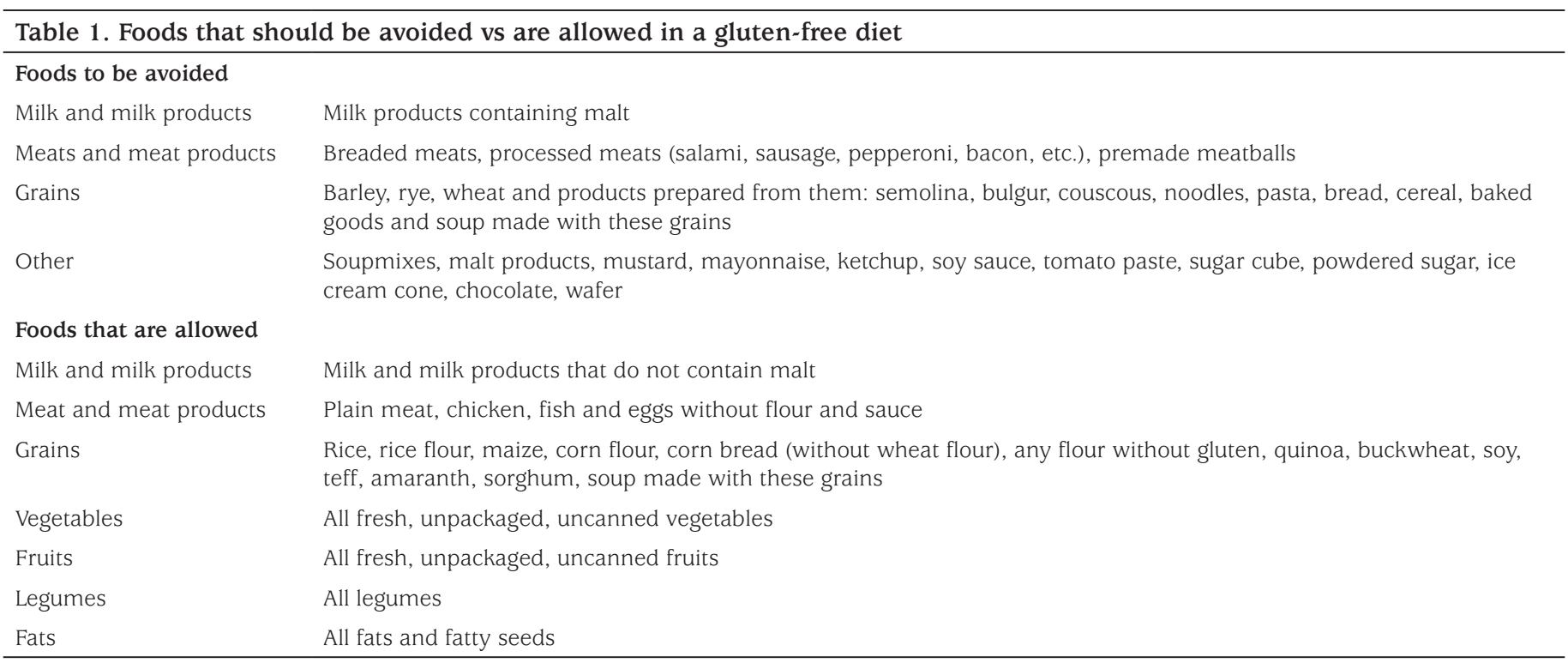

The table was adapted from reference 21 
9. The macronutrient composition of gluten-free products is different from that of their counterparts containing gluten. Most gluten-free foods are poor in protein and fiber, but rich in carbohydrates and fats with a high glycemic index $(26,27,28,29,30)$. Consequently, the glucose peaks in children with T1D and CD may be earlier and higher than those without CD (26). Accordingly, the dose and timing of insulin administration must be determined based on the nutrient content of the gluten-free products. Consumption of soup with meat/vegetables or salad prior to the main source of carbohydrate may improve postprandial glycemic control and dampen potential fluctuations $(30,31)$.

10. Increasing the variety of gluten-free foods may help improve the dietary compliance of children and adolescents with T1D and CD and help them achieve a better quality of life and control of their diabetes (26).

11. Commonly consumed gluten-free products, such as rice and potatoes, and packaged gluten-free items sold in the supermarkets have a high glycemic index. Instead, including products with a low glycemic index and high fiber content in the diet such as teff, amaranth, buckwheat, quinoa, sorghum, soy, vegetables, fruits with edible skin and legumes helps control the postprandial blood glucose levels $(26,27)$

12. However, some gluten-free products may be poor in carbohydrates and the administration of standard doses of insulin may result in severe hypoglycemia. Labels on food packages must be read and evaluated carefully $(28,29,30,31,32)$.

13. To reduce the occurrence of postprandial glucose peaks, meals should include sources of protein such as ayran, kefir, eggs, meat, chicken and fish (33).

14. When leaving the home children and adolescents with T1D should carry gluten-free carbohydrates to avoid the intake of products containing gluten to counteract episodes of hypoglycemia occurring outside the house $(28,29,30,31)$.

15. In addition to protein and fiber, micronutrients such as iron, calcium and B vitamins should be included in the diet to improve the overall benefit of the gluten-free diet $(23,32)$.

16. It may be challenging for children and adolescents with T1D and CD to follow a gluten-free diet. To improve dietary adherence, nutrition-centered education and regular counseling with a dietician specialized in pediatric diabetes management are essential (21).

17. In children with T1D, some parents may opt for a prophylactic gluten-free diet in the absence of a diagnosis of $\mathrm{CD}$ because of their awareness of this association. Nevertheless, there is no evidence to support that a gluten- free diet can prevent the development of $\mathrm{CD}$ in patients with T1D. Such an approach further complicates the management of diabetes in these patients. Moreover, gluten consumption is necessary to avoid false negative results and appropriately diagnose CD should it occur $(34,35)$.

18. There is no evidence to support the benefits of a glutenfree diet in individuals without $\mathrm{CD}$ or gluten intolerance. Therefore, the gluten-free diet cannot be a medical recommendation for such individuals $(34,35)$.

\section{Recommendations for Psychological Support}

1. Parents of children with $C D$ may report higher levels of anxiety, depression, aggression and sleep difficulties in their children, even before the definitive diagnosis is made or positive serology is detected (36). Therefore, pediatric endocrinology and gastroenterology specialists should be aware of the emotional and behavioral signs of $\mathrm{CD}$ and consider investigating for $\mathrm{CD}$ in children presenting with predominantly psychological and behavioral manifestations.

2. Studies show that childhood CD is a risk factor for mood disorders, anxiety disorders, eating disorders, behavioral disorders, attention deficit hyperactivity disorder, autism spectrum disorder and intellectual disability disorder (37). It is recommended for children with $\mathrm{CD}$ to be monitored into adulthood in terms of both physical and mental health.

3. Dealing with multiple chronic conditions can lead to poorer health outcomes, increasing financial costs and difficulties in the daily management of health. Although studies investigating the experiences of parents of children with T1D and $\mathrm{CD}$ are limited, families usually focus on health issues, financial concerns, psychological wellbeing of the child and social situations outside the house (38). Families worry more about the short and long-term complications of diabetes than those of CD. Routinely measuring blood glucose levels, counting carbohydrates and adhering to a strict gluten-free diet are likely to be some of the daily struggles for health management. Gluten-free products are very expensive and both preparing appropriate foods and doctor visits can take significant amounts of time. Children may feel different from their peers and suffer misunderstandings or bullying. False or incomplete information can lead to lack of physical and/or emotional support by society, especially in social settings such as schools.

\section{General Recommendations}

1. According to the results of a "questionnaire" conducted prior to the meeting, pediatric endocrinology and 
pediatric gastroenterology departments in Turkey exhibit heterogenous practice regarding the screening, diagnosis and management of $\mathrm{CD}$ in children with T1D, and $20 \%$ do not follow consensus guidelines. As such, greater cooperation between pediatric endocrinology and pediatric gastroenterology departments is necessary, which should be further supported by regular multidisciplinary team meetings that should include pathologists, dieticians and psychologists.

2. Standards for screening of $C D$ within the first five years following the diagnosis of $\mathrm{T} 1 \mathrm{D}$ should be set and implemented in clinics.

3. The main recommendations set forth by this script should be shared with ESPGHAN and ISPAD societies in order to request a joint consensus guideline for the diagnosis and management of children with T1D and CD.

4. Efforts should be made to improve the management of children with $\mathrm{CD}$ in schools and to garner greater governmental support.

\section{Acknowledgement}

The authors would like to thank Elif Özdoğan for her contributions on English translation of the manuscript.

\section{Ethics}

Peer-review: Externally peer-reviewed.

\section{Authorship Contributions}

Concept - Design - Data Collection or Processing - Analysis or Interpretation - Literature Search - Writing: All authors.

Financial Disclosure: The authors declared that this study received no financial support.

\section{References}

1. Pham-Short A, Donaghue KC, Ambler G, Phelan H, Twigg S, Craig ME. Screening for Celiac Disease in Type 1 Diabetes: A Systematic Review. Pediatrics 2015;136:170-176. Epub 2015 Jun 15

2. Al-Toma A, Volta U, Auricchio R, Castillejo G, Sanders DS, Cellier C, Mulder CJ, Lundin KEA; European Society for the Study of Coeliac Disease (ESsCD) guideline for coeliac disease and other gluten-related disorders. United European Gastroenterol J 2019;7:583-613. Epub 2019 Apr 13

3. Mahmud FH, Elbarbary NS, Fröhlich-Reiterer E, Holl RW, Kordonouri O, Knip M, Simmons K, Craig ME. ISPAD Clinical Practice Consensus Guidelines 2018: Other complications and associated conditions in children and adolescents with type 1 diabetes. Pediatr Diabetes 2018;19(Suppl 27):275-286.

4. Craig ME, Prinz N, Boyle CT, Campbell FM, Jones TW, Hofer SE, Simmons JH, Holman N, Tham E, Fröhlich-Reiterer E, DuBose S, Thornton H, King B, Maahs DM, Holl RW, Warner JT; Australasian Diabetes Data Network (ADDN); T1D Exchange Clinic Network (T1DX); National Paediatric Diabetes Audit (NPDA) and the Royal College of Paediatrics and Child Health; Prospective Diabetes Follow-up Registry
(DPV) initiative. Prevalence of Celiac Disease in 52,721 Youth with Type 1 Diabetes: International Comparison Across Three Continents. Diabetes Care 2017;40:1034-1040 Epub 2017 May 25

5. High rate of spontaneous normalization of celiac serology in a cohort of 446 children with type 1 diabetes: a prospective study. High rate of spontaneous normalization of celiac serology in a cohort of 446 children with type 1 diabetes: a prospective study. Diabetes Care 2015;38:760-766. Epub 2015 Mar 17

6. Poulain C, Johanet C, Delcroix C, Levy-Marchal C, Tubiana-Rufi N Prevalence and clinical features of celiac disease in 950 children with type 1 diabetes in France. Diabetes Metab 2007;33:453-458. Epub 2007 Oct 26

7. Al-Hussaini A, Sulaiman N, Al-Zahrani M, Alenizi A, El Haj I. High prevalence of celiac disease among Saudi children with type 1 diabetes: A prospective cross-sectional study. BMC Gastroenterol 2012;12:180.

8. Baptista ML, Koda YK, Mitsunori R, Nisihara, Ioshii SO. Prevalence of celiac disease in Brazilian children and adolescents with type 1 diabetes mellitus. J Pediatr Gastroenterol Nutr 2005;41:621-624.

9. Djurić Z, Stamenković H, Stanković T, Milićević R, Branković L, Cirić V, Katić V. Celiac disease prevalence in children and adolescents with type 1 diabetes from Serbia. Pdiatr Int 2010;52:579-583.

10. Boudraa G, Hachelaf W, Benbouabdellah M, Belkadi M, Benmansour FZ, Touhami M. Prevalence of coeliac disease in diabetic children and their first- degree relatives in west Algeria: Screening with serological markers. Acta Paediatr Suppl 1996;412:58-60.

11. Sari S, Yeşilkaya E, Eğritaş O, Bideci A, Cinaz P, Dalgiç B. Prevalence of Celiac disease in Turkish children with type 1 diabetes mellitus and their non-diabetic first-degree relatives. Turk J Gastroenterol 2010;21:34-38.

12. Ertekin V, Selimoglu MA, Doneray H, Orbak Z, Ozkan B. Prevalence of celiac disease in a sample of Turkish children and adolescents with type 1 diabetes mellitus. J Clin Gastroenterol 2006;40:655-657.

13. Puñales $M$, Bastos MD, Ramos ARL, Pinto RB, Ott EA, Provenzi V, Geremia C, Soledade MA, Schonardie AP, da Silveira TR, Tschiedel B. Prevalence of celiac disease in a large cohort of young patients with type 1 diabetes. Pediatr Diabetes 2019;20:414-420. Epub 2019 Apr 3

14. Wessels M, Velthuis A, van Lochem E, Duijndam E, Hoorweg-Nijman G, de Kruijff I, Wolters V, Berghout E, Meijer J, Bokma JA, Mul D, van der Velden J, Roovers L, Mearin ML, van Setten P. Raising the Cut-Off Level of Anti-Tissue Transglutaminase Antibodies to Detect Celiac Disease Reduces the Number of Small Bowel Biopsies in Children with Type 1 Diabetes: A Retrospective Study. J Pediatr 2020;223:87-92. Epub 2020 May 4

15. Unal E, Demiral M, Baysal B, Ağın M, Devecioğlu EG, Demirbilek H, Özbek MN. Frequency of Celiac Disease and Spontaneous Normalization Rate of Celiac Serology in Children and Adolescent Patients with Type 1 Diabetes. J Clin Res Pediatr Endocrinol 2021;13:72-79. Epub 2020 Aug 21

16. Robert ME, Crowe SE, Burgart L, Yantiss RK, Lebwohl B, Greenson JK, Guandalini S, Murray JA. Statement on Best Practices in the Use of Pathology as a Diagnostic Tool for Celiac Disease: A Guide for Clinicians and Pathologists. Am J Surg Pathol 2018;42:44-58.

17. Ensari A. Gluten-sensitive enteropathy (celiac disease): controversies in diagnosis and classification. Arch Pathol Lab Med 2010;134:826-836.

18. Rubio-Tapia A, Hill ID, Kelly CP, Calderwood AH, Murray JA; American College of Gastroenterology. ACG clinical guidelines: diagnosis and management of celiac disease. Am J Gastroenterol 2013;108:656-677. Epub 2013 Apr 23

19. Walker MM, Ludvigsson JF, Sanders DS. Coeliac disease: review of diagnosis and management. Med J Aust 2017;207:173-178. 
20. Koehler $\mathrm{P}$, Wieser $\mathrm{H}$, Konitzer $\mathrm{K}$. Celiac disease and gluten: multidisciplinary challenges and opportunities. United States of America, Academic Press, 2014;149-156.

21. Schwarzenberg SJ, Brunzell C. Type 1 diabetes and celiac disease: Overview and medical nutrition therapy. Diabetes Spectrum 2002;15:197-201.

22. Johnson AN, Skaff AN, Senesac L. Medication and supplement use in celiac disease. US Pharm 2014;39:44-48.

23. Kupper C, Higgins LA. Combining diabetes and gluten-free dietary management guidelines. Practical Gastroenterology 2007:68-83.

24. Bascuñán KA, Vespa MC, Araya M. Celiac disease: understanding the gluten-free diet. Eur J Nutr 2017;56:449-459. Epub 2016 Jun 22

25. Kahlon TS, Chiu MCM. Teff, Buckwheat, Quinoa and Amaranth: Ancient Whole Grain Gluten-Free Egg-Free Pasta. Food and Nutrition Sciences 2015;6:1460-1467.

26. Pham-Short A, Donaghue KC, Ambler G, Garnett S, Craig ME. Greater postprandial glucose excursions and inadequate nutrient intake in youth with type 1 diabetes and celiac disease. Sci Rep 2017;7:45286.

27. Foster-Powell K, Holt SH, Brand-Miller JC. International table of glycemic index and glycemic load values: 2002. Am J Clin Nutr 2002;76:5-56.

28. Camarca ME, Mozzillo E, Nugnes R, Zito E, Falco M, Fattorusso V, Mobilia S, Buono S, Valerio G, Troncone R, Franzese A. Celiac disease in type 1 diabetes mellitus. Ital J Pediatr 2012;38:1-7.

29. Kaur N, Bhadada SK, Minz RW, Dayal D, Kochhar R. Interplay between Type 1 Diabetes Mellitus and Celiac Disease: Implications in Treatment. Dig Dis 2018;36:399-408. Epub 2018 Jul 25

30. Rodbard D. Optimizing the Estimation of Carbohydrate-to-Insulin Ratio and Correction Factor. Diabetes Technol Ther 2018;20:94-97.
31. Bell KJ, Smart CE, Steil GM, Brand-Miller JC, King B, Wolpert HA. Impact of fat, protein, and glycemic index on postprandial glucose control in type 1 diabetes: implications for intensive diabetes management in the continuous glucose monitoring era. Diabetes Care 2015;38:10081015.

32. Scaramuzza AE, Mantegazza C, Bosetti A, Zuccotti GV. Type 1 diabetes and celiac disease: The effects of gluten free diet on metabolic control. World J Diabetes 2013;4:130-134.

33. Paterson MA, Smart CEM, Lopez PE, Howley P, McElduff P, Attia J, Morbey $C$, King BR. Increasing the protein quantity in a meal results in dose-dependent effects on postprandial glucose levels in individuals with Type 1 diabetes mellitus. Diabet Med 2017;34:851-854. Epub 2017 Mar 19

34. Jones AL. The gluten-free diet: fad or necessity? Diabetes Spectr 2017;30:118-123.

35. Serena G, Camhi S, Sturgeon C, Yan S, Fasano A. The role of gluten in celiac disease and type 1 diabetes. Nutrients 2015;7:7143-7162.

36. Smith LB, Kurppa K, Agardh D. Further Support for Psychological Symptoms in Pediatric Celiac Disease. Pediatrics 2019;144:20191683. Epub 2019 Sep 6

37. Butwicka A, Lichtenstein P, Frisén L, Almqvist C, Larsson H, Ludvigsson JF. Celiac disease is associated with childhood psychiatric disorders: a population-based study. J Pediatr 2017;184:87-93. Epub 2017 Mar 7

38. Erickson K, Freeborn D, Roper SO, Mandleco B, Anderson A, Dyches T. Parent experiences raising young people with type 1 diabetes and celiac disease. J Pediatr Nurs 2015;30:353-363. Epub 2014 Oct 2 